\title{
A Phase II trial of intravenous bevacizumab, paclitaxel and intraperitoneal cisplatin followed by intravenous bevacizumab maintenance for treatment of stage II-III ovarian cancer
}

\author{
Grainger L. Lanneau ${ }^{1}$, LaToya J. Perry ${ }^{2}$, Kathleen N. Moore ${ }^{3}$,Julie CurielRN ${ }^{3}$, Michael A. Gold ${ }^{4}$, Robert S. Mannel ${ }^{3}$ Joan L. Walker ${ }^{3}$ and D \\ Scott McMeekin ${ }^{3}$ \\ ${ }^{1}$ Naval Medical Center, San Diego, CA, USA \\ ${ }^{2}$ Cadence Physician Group, Winfield, IL,USA \\ ${ }^{3}$ Stephenson Oklahoma Cancer Center at the University of Oklahoma. Oklahoma City, OK, USA \\ ${ }^{4}$ Tulsa Cancer Institute, Tulsa OK,USA
}

\begin{abstract}
Objective: Acceptance of intraperitoneal (IP) chemotherapy has not been widespread with anticipated toxicity commonly cited as a limitation of this therapy. We evaluated a modified IP regimen with IV bevacizumab to determine feasibility and assess toxicities.

Methods: A phase II study was conducted in patients with advanced ovarian cancer following cytoreduction to $<1 \mathrm{~cm}$ residual disease. The primary aim was to evaluate feasibility as defined as completion of 6 cycles. Patients received IV paclitaxel $135 \mathrm{mg} / \mathrm{m}^{2}$ and IV bevacizumab $15 \mathrm{mg} / \mathrm{kg}$ (cycle $2-6$ ) on day 1 followed by cisplatin $75 \mathrm{mg} / \mathrm{m}^{2}$ IP day 2, repeated every 21 days x 6 cycles. Following primary therapy, patients received IV bevacizumab $15 \mathrm{mg} / \mathrm{kg}$ maintenance q21 days x 12 cycles. The FACT GOG NTX tool was used to prospectively monitor neuropathy scores over treatment.

Results: 20 evaluable patients are presented including $85 \%$ with stage III disease, and $75 \%$ with no gross residual. $85 \%$ received 6 cycles of IP therapy and $77 \%$ of these received all 12 cycles of maintenance. Scores for neuropathy worsened through cycle 6 , peaked at 9 and improved by 18 . Toxicity was acceptable with neutropenia the most common grade 3-4 adverse event, and 8 patients experienced grade 2-3 neuropathy. With a median follow-up of 63 months, the median PFS and OS is 50 and 71 months respectively.
\end{abstract}

Conclusions: Adding IV bevacizumab to a modified IP regimen is feasible. As compared to GOG 172, the lower cisplatin dose and omission of day 8 IP paclitaxel may allow a higher completion rate. Despite modifications, neuropathy remains important issue in IP based cisplatin regimens.

\section{Introduction}

Ovarian cancer is the leading cause of death from gynecologic cancer in the United States [1]. The high death rate stems from late presentation and tumor that has spread beyond the ovary and throughout the peritoneal cavity at the time of diagnoses [2]. Three randomized clinical trials have demonstrated the superiority of intraperitoneal (IP) over intravenous (IV) platinum based chemotherapy in patients with optimally debulked advanced stage ovarian cancer [3-5] (Table 1). The most recent is Gynecologic Oncology Group (GOG) protocol 172; a phase III randomized trial comparing IV paclitaxel plus cisplatin versus IV paclitaxel $\left(135 \mathrm{mg} / \mathrm{m}^{2}\right.$ over 24 hours on day 1) plus IP cisplatin (100 $\mathrm{mg} / \mathrm{m}^{2}$ on day 2$)$ and IP paclitaxel $\left(60 \mathrm{mg} / \mathrm{m}^{2}\right.$ on day 8$)$ in patients with $<1 \mathrm{~cm}$ residual disease. Both progression-free (PFS) (median, $18.3 \mathrm{vs}$. 23.8 months) and overall survival (OS) (median, 49.7 vs. 65.6 months) was significantly improved with the IP regimen [5].

Widespread acceptance of this IP regimen was not seen because of toxicities associated with the therapy [6]. Only $42 \%$ of women on the IP arm of GOG 172 received 6 cycles of therapy, and $49 \%$ received 3 or fewer cycles [5]. Patients who were randomized to the IP therapy group in GOG-172 had higher rates of adverse events for neurologic, gastrointestinal, metabolic, infection, febrile, and hematologic toxicities [6].

Parallel with the studies of IP therapies have been investigations of targeted therapies, specifically those that target angiogenesis. Phase II studies demonstrated single agent activity of the VEGF antibody, bevacizumab, [7-9] and two phase III studies in front-line therapy were initiated based on the premise that combining chemotherapy with bevacizumab or maintenance bevacizumab following chemotherapy would improve outcomes $[10,11]$. The pivotal phase III GOG 218 trial demonstrated progression-free survival (PFS) benefit in patients who received concurrent and maintenance bevacizumab compared with

Correspondence to: Kathleen N. Moore, MD, Stephenson Oklahoma Cancer Center, $800 \mathrm{NE} 10^{\text {th }}$ St Oklahoma City, Oklahoma 73121, USA, Tel: 405-2718707; Fax: 405-271-2976, E-mail: kathleen-moore@ouhsc.edu

Received: September 30, 2015; Accepted: October 22, 2015; Published: October 26, 2015 
Lanneau GL (2015) A Phase II trial of intravenous bevacizumab, paclitaxel and intraperitoneal cisplatin followed by intravenous bevacizumab maintenance for treatment of stage II-III ovarian cancer

Table 1. Phase III IP based clinical trials.

\begin{tabular}{|l|l|l|}
\hline Study & PFS (median) & OS (median) \\
\hline $\begin{array}{l}\text { SWOG/GOG-104 } \\
\text { Alberts } \text { et al. } \text { [4] }\end{array}$ & 49 mo (IP) $v s .41 \mathrm{mo}$ (IV), $\mathrm{p}=0.02$ \\
\hline $\begin{array}{l}\text { GOG-114/SWOG } \\
\text { Markman } \text { et al. }[3]\end{array}$ & 28 mo (IP) $v$ s. 22 (IV), $\mathrm{p}=0.01$ & 63 mo (IP) $v s .52$ (IV), $\mathrm{p}=0.05$ \\
\hline $\begin{array}{l}\text { GOG-172 } \\
\text { Armstrong } \text { et al. } \text { [5] }\end{array}$ & 24 mo (IP) $v s .18$ (IV), $\mathrm{p}=0.05$ & 65.6 mo (IP) $v s .49 .7$ (IV), $\mathrm{p}=0.03$ \\
\hline
\end{tabular}

chemotherapy alone (14.1 months vs. 10.3 months; hazard ratio (HR) $0.717, \mathrm{p}<0.001)$. However, there was no difference in overall survival (OS) reported [10]. A subset analysis was performed on the patients with stage IV disease who received bevacizumab and did find an OS benefit of 40.6 compared to 32.8 months (HR=0.72; 95\% CI 0.53-0.97) [12]. In parallel ICON 7 demonstrated an improvement in PFS (19 vs. 17.3 months; HR 0.81, $\mathrm{p}=0.004$, no improvement in OS except in those with stage IV and sub-optimal residual disease who had a median OS of 39.7 vs. 30.3 months [13].

This study sought to enhance IP chemotherapy delivery by reducing toxicity as well as combine IP chemotherapy with IV bevacizumab which had not been widely reported at the time of study inception. We sought to evalute the feasibiltiy of administering a modification of the GOG 172 IP regimen with the addition of IV bevacizumab. Feasibility would be judged based on the ability to complete 6 cycles of therapy and on the toxicity profile of the regimen.

\section{Methods}

After institutional review board approval, an open label phase II study was conducted in patients with stage II-III ovarian (epithelial and carcinosarcoma), fallopian tube, or primary peritoneal cancers with residual disease $\leq 1 \mathrm{~cm}$ following initial CRS. The primary aim of the study was to evaluate the feasibility of delivering IP cisplatin with IV paclitaxel and IV bevacizumab as defined by the proportion of patients able to complete 6 cycles of the IP based treatment. Eligible patients had a GOG performance status of 0-1, normal baseline hematologic, renal, and hepatic laboratory values, and had a protein/urine creatinine ratio $<1.0$. All patients were to be treated within 12 weeks of surgery. Patients with borderline tumors or stage IV disease were excluded. Patients with significant cardiovascular history, uncontrolled hypertension, or nonhealing wounds were excluded. IP ports were placed either at the time of initial surgery or as a secondary procedure using the recommended surgical approaches from the GOG surgical manual.

Patients received IV paclitaxel $135 \mathrm{mg} / \mathrm{m}^{2}$ over 3 hours and IV bevacizumab $15 \mathrm{mg} / \mathrm{kg}$ (cycle 2-6) on day 1 followed by IP cisplatin $75 \mathrm{mg} / \mathrm{m}^{2}$ IP on day 2 . Patients received standard hypersensitivity prophylaxis and anti-emetic medications. All patients received pre- and post- cisplatin hydration on day 2 with $2 \mathrm{~L}$ normal saline administered IV over 2-4 hours. Cycles were administered every 21 days for a total of 6 cycles. Following completion of primary therapy, IV bevacizumab at $15 \mathrm{mg} / \mathrm{kg}$ IV was given as maintenance therapy every 21 days for 12 cycles or until disease progression or excessive toxicity.

Patients were seen each cycle and toxicities were recorded and graded by the NCI common toxicity criteria version 3.0. In addition, the FACT-GOG/ NTX4 neuropathy assessement tool was administered at baseline, following cycles 3 and 6 , then after every cycle during maintneance therapy [14]. Dose delays and modifications were used to manage significant neuropathy, neutropenia, or thrombocytopenia. Blood count recovery to an absolute neutrophil count (ANC) $\geq 1500 /$ $\mathrm{mm}^{3}$ and platelets $\geq 100,000 / \mathrm{mm}^{3}$ were required to treat for the subsequent cycle. Patients were removed from study if a delay of $>3$ weeks was required. Patients were required to maintain a home log of their blood pressures and these were assessed prior to each treatment and used to assess whether bevacizumab would be administered. If blood pressure was $\leq 150 \mathrm{~mm} / \leq 90 \mathrm{~mm} \mathrm{Hg}$ bevacizumab was continued. Grade 3 hypertension (HTN) was managed by use of anti-hypertensive medications and treatment delays, and grade 4 HTN required discontinuation of bevacizumab. Proteinuria was monitored prior to every cycle using the protein creatinine ratio, and were continued on treatment provided the ratio was $<3.5$.

\section{Statistics}

The GOG 172 study suggested that completion rates of 6 cycles of IP based therapy was $\sim 40 \%$. It was felt that improving the rate of successful completion to $80 \%$ would be clinically relevant. With a sample size of 20 patients, 13 or more completing therapy would exceed the historical rate of completion (40\%) (95\% CI 13/20: 40.7-84.6\%).

Patients were assessed each treatment cycle, then every 3 months for two years, then every 6 months for 3 years. Imaging studies were performed based on presence of symptoms, clinical findings, or rising CA125 levels. PFS was measured from start of treatment to disease progression and OS was measured from diagnosis to death or last follow up.

\section{Results}

From August 2007 to September 2008, 22 patients were enrolled in the study and 20 were evaluable for feasibility of completion of 6 cycles. Of the 20 evaluable patients, median age was 59 years, $85 \%$ had stage III disease, $60 \%$ had high-grade and $20 \%$ had low-grade serous tumors (Table 2). All patients underwent primary CRS and were left with $<1$ $\mathrm{cm}$ residual disease (75\% no gross).

During the cytotoxic treatment phase, 3 patients were unable to complete all 6 cycles of therapy. One patient had an IP port complication at cycle 4 , another had persistent grade 3 neuropathy after cycle 4 , and 1 patient received 5 cycles of IP based therapy but due to grade 3 abdominal pain with IP therapy received cycle 6 intravenously. Overall,

Table 2. Clinical-pathologic characteristics of enrolled patients.

\begin{tabular}{|c|c|c|}
\hline $\begin{array}{l}\text { Variable } \\
\mathbf{N}=\mathbf{2 0}\end{array}$ & N (\%) & $\%$ \\
\hline Age & Median & 59 yrs \\
\hline Stage & $\begin{array}{l}1 \text { IIB } \\
2 \text { IIC } \\
2 \text { IIIA } \\
1 \text { IIIB } \\
14 \text { IIIC }\end{array}$ & $\begin{array}{l}15 \% \text { Stage II } \\
85 \% \text { Stage III }\end{array}$ \\
\hline Histology & $\begin{array}{l}12 \text { High Grade Serous } \\
4 \text { Low Grade Serous } \\
4 \text { Non-serous } \\
1 \text { Endometrioid } \\
1 \text { Mucinous } \\
1 \text { Clear cell } \\
1 \text { Carcinosarcoma }\end{array}$ & $\begin{array}{l}60 \% \\
20 \% \\
15 \%\end{array}$ \\
\hline Residual Disease & $\begin{array}{l}15 \text { No gross } \\
5 \text { Gross, }<1 \mathrm{~cm}\end{array}$ & $\begin{array}{l}75 \% \\
25 \%\end{array}$ \\
\hline
\end{tabular}


Lanneau GL (2015) A Phase II trial of intravenous bevacizumab, paclitaxel and intraperitoneal cisplatin followed by intravenous bevacizumab maintenance for treatment of stage II-III ovarian cancer

$17 / 20(85 \%)$ patients enrolled in the study completed 6 IP cycles of primary therapy.

Of the 17 patients who completed 6 cycles of combined IP chemotherapy with IV bevacizumab, $13 / 17$ (77\%) were able to receive all 12 cycles of maintenance therapy. One patient developed an entero-vesical fistula after completion of 6 cycles of therapy and did not continue on to maintenance therapy. One patient discontinued due to disease progression as well as grade 3-hypertension at cycle 8; 1 withdrew at cycle 9 secondary to fatigue (grade 3 ), and 1 patient withdrew at cycle 11 secondary to a personal hardship preventing completion of cycle 12. With a median follow-up of 63 months, 9/20 (45\%) patients remain without recurrence. The median progressionfree survival is 50 months and median overall survival is 71 months.

Adverse events recorded during the cytotoxic treatment phase (IP chemotherapy plus IV bevacizumab) were based on the frequency of AEs during 113 cycles of administered IP chemotherapy (Table 3). Only neutropenia (35\%) and nausea (13\%) were associated with a $>10 \%$ frequency of grade 3-4 adverse events. Five and 3 patients respectively, reported grade 2 and 3 neuropathy. There were a total of 10 grade 3 or 4 toxicities during the maintenance phase of therapy. One patient had 4 episodes of grade 3 neutropenia that was ultimately improved with GSF support. One patient was noted to have transient elevation of transaminases (grade 3) that improved without intervention. Another patient had an IV port infection requiring antibiotic therapy. As noted above, one patient with bilateral hydronephrosis secondary to disease progression and grade 3-hypertension came off study. Three patients reported grade 3 fatigue, of which 2 patients came off study before completion of maintenance therapy (Table 3).

The Fact-GOG NTX subscale instrument demonstrated a steady rate of increase in the NTX scores over cycle 1-6 (Figure 1). The rate of increase remained the same from cycles 6-9, despite IP chemotherapy being discontinued. The mean scores at cycle 9 were 3 fold higher than at cycle $6(\mathrm{p}=0.009)$. By cycle 18 there was recovery in NTX scores to a level seen following cycle $6(\mathrm{p}=0.15)$. Longer term NTX evaluation following 18 cycles was not performed. Statistical testing using a Spline model with knot at cycle 9 estimated a non-significant increasing trend and slope from cycle 9 to 18 (95\% CI $-0.4719,0.3528)$.

\section{Discussion}

Despite 3 positive phase III trials supporting IP chemotherapy [35], and a resulting NCI Clinical Announcement in 2006 recommending its use [15], IP therapy for advanced ovarian cancer has not been widely embraced. The grade 3-4 toxicity associated with GOG 172 included 4 times higher rates of fatigue, 3 times more infections and metabolic events, and a doubling in neurologic toxicity with the IP regimen [5]. In addition, only $42 \%$ of patients successfully completed 6 cycles of therapy. Yet, the overall survival difference favored IP therapy by nearly 16 months.

Following the publication of GOG 172 in 2006, the GOG instituted several phase Ib/II feasibility trials (GOG 9916, 9917, 9921)] (Table 4) in an effort to develop alternative IP regimens which permitted an increase in the proportion of patients who successfully completed IP based regimens and reduce noted toxicities associated with prior studies. [16-18]. The modifications included substituting IP carboplatin for IP cisplatin, or substituting IV docetaxel for IV paclitaxel both while maintaining the day 8 IP paclitaxel (9916); substituting IP carboplatin for IP cisplatin and dropping the day 8 IP paclitaxel (9917) or dose reduction of the IP cisplatin from $100 \mathrm{mg} / \mathrm{m}^{2}$ to $75 \mathrm{mg} / \mathrm{m}^{2}$ (9921) [16-18].
Table 3. Adverse events recorded during the IP/IV phase (Cycles 1-6,) of therapy.

\begin{tabular}{|c|c|c|c|c|}
\hline CTCAE, v. 3.0 Grade & 1 & 2 & 3 & 4 \\
\hline \multicolumn{5}{|l|}{ Adverse Effect } \\
\hline Hemoglobin & 72 & 15 & 1 & 1 \\
\hline Platelets & 12 & 1 & 1 & 0 \\
\hline ANC/AGC & 7 & 16 & 39 & 39 \\
\hline Allergy & 0 & 0 & 0 & 0 \\
\hline Hearing & 2 & 9 & 0 & 0 \\
\hline Cardiovascular- HTN & 1 & 4 & 3 & 0 \\
\hline Coagulation & 0 & 1 & 1 & 0 \\
\hline Fatigue & 57 & 33 & 4 & 0 \\
\hline Constitutional- other & 1 & 0 & 0 & 0 \\
\hline Dermatologic-rash & 7 & 0 & 0 & 0 \\
\hline Hyperglycemia & 40 & 6 & 5 & 0 \\
\hline Gastrointestinal- Nausea & 39 & 16 & 6 & 0 \\
\hline Anorexia & 30 & 20 & 9 & 0 \\
\hline Constipation & 32 & 14 & 0 & 0 \\
\hline Diarrhea & 24 & 6 & 0 & 0 \\
\hline Stomatitis & 15 & 5 & 0 & 0 \\
\hline Genitourinary/Renal & 15 & 2 & 0 & 0 \\
\hline Hemorrhagic & 7 & 0 & 0 & 0 \\
\hline Hepatic & 7 & 0 & 1 & 0 \\
\hline Infection & 12 & 8 & 3 & 0 \\
\hline Metabolic & 50 & 4 & 5 & 0 \\
\hline Sensory neuropathy & 33 & 5 & 3 & 0 \\
\hline Ocular & 11 & 7 & 0 & 0 \\
\hline Pain- myalgia & 16 & 11 & 0 & 0 \\
\hline Pain- arthralgia & 13 & 4 & 1 & 0 \\
\hline Pulmonary & 21 & 4 & 1 & 0 \\
\hline Sexual/Hot Flash & 28 & 11 & 0 & 0 \\
\hline Abdominal pain & 32 & 5 & 3 & 0 \\
\hline Headache & 12 & 7 & 4 & 0 \\
\hline
\end{tabular}

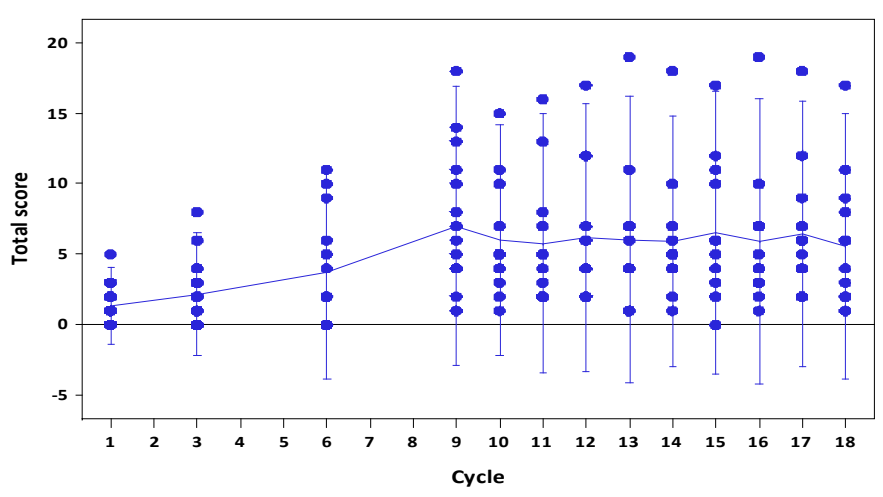

Figure 1. Neuropathy scores over cycles of chemotherapy as measured by the GOG NTX instrument [14]. 
Lanneau GL (2015) A Phase II trial of intravenous bevacizumab, paclitaxel and intraperitoneal cisplatin followed by intravenous bevacizumab maintenance for treatment of stage II-III ovarian cancer

Table 4. Modifications of GOG 172 in clinical trials

\begin{tabular}{|c|c|c|}
\hline Study & Regimen/Dose & Completed IP Rx \\
\hline GOG 172 Armstrong et al. [5] & $\begin{array}{l}\text { P } 135 \mathrm{IV} \mathrm{mg} / \mathrm{m}^{2}(24 \mathrm{hr}) \text { - day } 1 \text {, CDDP IP } 100 \mathrm{mg} / \mathrm{m}^{2} \text { - day } 2 \text {, } \\
\text { P IP } 60 \mathrm{mg} / \mathrm{m}^{2} \text {-day } 8\end{array}$ & $42 \%$ \\
\hline $\begin{array}{l}\text { GOG } 9916 \\
\text { Gould } \text { et al. [16 ] }\end{array}$ & 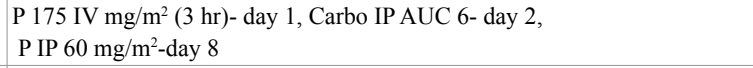 & $65 \%$ \\
\hline $\begin{array}{l}\text { GOG } 9916 \\
\text { Gould } \text { et al. }[16]\end{array}$ & $\begin{array}{l}\text { Doc } 75 \mathrm{IV} \mathrm{mg} / \mathrm{m}^{2}(24 \mathrm{hr}) \text { - day } 1 \text {, Carbo IP AUC } 6 \text { day } 1 \text {, } \\
\text { P IP } 60 \mathrm{mg} / \mathrm{m}^{2} \text {-day } 8\end{array}$ & Not feasible for 6 cycles of therapy \\
\hline $\begin{array}{l}\text { GOG } 9917 \\
\text { Morgan et al. }[18]\end{array}$ & 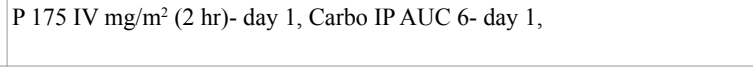 & $75 \%$ \\
\hline $\begin{array}{l}\text { GOG } 9921 \\
\text { Dizon } \text { et al. [17] }\end{array}$ & $\begin{array}{l}\text { P } 135 \mathrm{IV} \mathrm{mg} / \mathrm{m}^{2}(3 \mathrm{hr}) \text { - day } 1 \\
\text { CDDP IP } 75 \mathrm{mg} / \mathrm{m}^{2} \text { - day } 1, \\
\text { P IP } 60 \mathrm{mg} / \mathrm{m}^{2} \text {-day } 8\end{array}$ & $95 \%$ \\
\hline Konner et al. [21] & $\begin{array}{l}\text { P } 135 \mathrm{IV} \mathrm{mg} / \mathrm{m}^{2}(3 \mathrm{hr}) \text { - day } 1 \text {, } \\
\text { CDDP IP } 75 \mathrm{mg} / \mathrm{m}^{2} \text { - day } 2 \text {, } \\
\text { P IP } 60 \mathrm{mg} / \mathrm{m}^{2} \text {-day } 8 \\
\text { Bev } 15 \mathrm{mg} / \mathrm{kg} \text { - day } 1 \text { ( } \text { (tart cycle } 2) \rightarrow \text { then Bev maintenance for } 17 \text { cycles }\end{array}$ & $73 \%$ \\
\hline Present Study & $\begin{array}{l}\text { P } 135 \mathrm{IV} \mathrm{mg} / \mathrm{m}^{2} \text { ( } 3 \mathrm{hr} \text { )- day } 1 \text {, } \\
\text { CDDP IP } 75 \mathrm{mg} / \mathrm{m}^{2} \text { - day } 2 \text {, } \\
\text { Bev } 15 \mathrm{mg} / \mathrm{kg} \text { - day } 1 \text { (start cycle } 2) \rightarrow \text { then Bev maintenance for } 12 \text { cycles }\end{array}$ & $85 \%$ \\
\hline
\end{tabular}

The primary endpoint of these studies, following the determination of maximum tolerated doses, was feasibility of adminstering the regimen without an excessive frequncy of grade 3-4 adverse events. In addition, studies were more proactive in specifying supportive care during therapy in an effort to manage or reduce toxicity. None of these trials included bevacizumab.

Given the difficulty in administering the GOG 172 IP regimen and excitement regarding the addition of bevacizumab to front line therapy, we evaluated a modified GOG-172 outpatient regimen and added IV bevacizumab both concurrently with and following IP chemotherapy. Our results showed that $85 \%$ of patients were able to complete 6 cycles of therapy, and $77 \%$ of these patients were able to receive 12 additional cycles of maintnenance bevacizumab. With a median follow up of 63 months, $45 \%$ of patients remain recurrence free, with a median PFS and $O S$ of 50 and 71 months respectively.

We decreased the dose of IP cisplatin to $75 \mathrm{mg} / \mathrm{m}^{2}$ from $100 \mathrm{mg} / \mathrm{m}^{2}$ to lessen the metabolic, neurotoxic and renal complications of cisplatin and used aggressive pre and post dose hydration. Dose response studies with cisplatin have not shown marked differences in outcome in the $50-100 \mathrm{mg} / \mathrm{m}^{2}$ range when given intravenously [19]. We speculate that the reduced IP cisplatin dose would still expose the cancer cells in the peritoneum to platinum concentrations up to 20 fold greater than that achieved with systemic therapy [20]. We also eliminated day 8 paclitaxel in an effort to reduce neurotoxicity noted with GOG 172, but not seen in earlier IP trials with cisplatin.

\section{Completion of 6 cycles of chemotherapy}

In this study, with a drop in the dose of IP cisplatin and elimination of day 8 IP paclitaxel along with the addition of IV bevacizumab, we report a 6 cycle completion rate of $85 \%$.

Konner and colleagues reported on a similar trial including 41 patients using an IP based regimen with $3 \mathrm{hr}$ IV paclitaxel $(135 \mathrm{mg} /$ $\mathrm{m}^{2}$ ), IP cisplatin at $75 \mathrm{mg} / \mathrm{m}^{2}$, however, they maintained the day 8 IP paclitaxel $\left(60 \mathrm{mg} / \mathrm{m}^{2}\right)$ infusion and then combined this with IV bevacizumab/ bevacizumab maintnenance (X 17 cycles). They found that $73 \%$ received 6 cycles of therapy, and $36 \%$ recived all planned doses of chemotherapy followed by bevacizumab consolidation[21]. Barlin et al. [22] reported on 102 patients who received $3 \mathrm{hr}$ IV paclitaxel (135 $\left.\mathrm{mg} / \mathrm{m}^{2}\right)$, IP cisplatin at $75 \mathrm{mg} / \mathrm{m}^{2}$, and day $8 \mathrm{IP}$ paclitaxel $\left(60 \mathrm{mg} / \mathrm{m}^{2}\right)$. They had $6 \%$ grade $3 / 4$ neurologic complications and $55 \%$ completed all 6 cycles.

Completion of 6 cycles is an important endpoint as demonstrated by Tewari et al. [23]. In an ancillary analysis of GOG 114 and 172, the risk of death decreased by $12 \%$ for each cycle of IP chemotherapy completed by any patient (adjusted HR 0.88; 95\% CI, $0.83-0.94$; $\mathrm{p}<0.001$ ). Looking only at the 172 patients, completion of 6 cyces of IP chemotherapy was associted with better survival compared with 3 cycles of IP followed by 3 cycles of IV.

In GOG 172, catheter complications accounted for $33 \%$ of patients who completed $<6$ cycles of IP chemotherapy [24]. In our study, $2 / 22$ (4.5\%) of patients discontinued therapy ( 1 after cycle 1,1 after cycle 4) due to IP port complications. In Konner's study, 3 patients (7\%) experienced a port malfunction. It appears that adding bevacizumab does not increase the rate of port complications appreaciably.

\section{Neuropathy}

We prospectively monitored patient reported outcomes of neuropathy using validated survey instruments. Abdominal pain was reported in $6 \%$ of IP cycles administered including 1 patient who discontinued IP therapy at cycle 6 . There were 5 patients with grade 2 and 3 with grade 3 neuropathy including one patient who discontinued therapy at cyce 5 for grade 3 neuropathy. Konner and colleagues reported $7 \%$ of patients had grade 3 abdominal pain, and there was no report of neuropathy. Patient reported outcomes were not prospectively monitored however. Barlin et al. [22] reported 6\% G3/4 neuropathy.

Using the GOG NTX tool we found that even after completing IP chemotherapy at cycle 6 , neuropathy scores worsened during bevacizumab maintnenance from cyles 6 to 9 (first 3 maintenence cycles), then had recovery to the post $6^{\text {th }}$ cycle levels by cycle 18 . This might suggest that bevacizumab delays recovery from sensory neuropathy occuring following paclitaxel/platinum chemotherapy. However, in the health related quality of life anlaysis from GOG 172, chemotherapy induced neuropathy as measured by the NTX subscale worsened on both arms but more so on the IP arm. Even during the follow up period post therapy, there were higher (worse) NTX subscale 
Lanneau GL (2015) A Phase II trial of intravenous bevacizumab, paclitaxel and intraperitoneal cisplatin followed by intravenous bevacizumab maintenance for treatment of stage II-III ovarian cancer

scores among those patients in the IP arm $(\mathrm{p}<0.001)$ [25] This data suggests that the neuropathy induced by IP cisplatin may worsen and persist following chemotherapy independent of use of maintenance bevacizumab.

Larger prospective trials including bevacizumab have shown consistent results that chemotherapy produces neuropathy that extends beyond the treatment period. For example in GOG 218, using the FACT-O-TOI tool (cycles 1, 4, 7, 13 and 21 as well as 6 months after completion), analysis showed significantly lower FACT-O-TOI scores in both bevacizumab containing arms primarily at cycle 4 and persisting to cycle 7 . There were no differences between the no bevacizumab and bevacizuamb maintenace arm during the maintenance portion of therapy [26].

In the GOG 240 trial, a study of chemotherapy with or without bevacizumab in advanced/recurrent cervix cancer, the percentage of patients reported neurotoxicity symptoms increased over time in both the bevacizumab and non bevacizumab groups. However, the patients on bevacizumab reported neurotoxicity less frequently than those who were not on bevaizumab (OR 0.58 (98\% -75\% CI: 0.17-0.98)). Further, the FACT/GOG-Ntx score did not differ in severity when neuropathy was present between the two groups. (difference 0.23 (98-75\% CI: 1.19 to $1.64 ; \mathrm{p}=0.69))$ [27].

\section{GI Toxicity}

Konner noted 3 cases of grade 3 small bowel obstruction (7\%), and 1 case of anastomatic dehiscence (following cycle 4) which resulted in death. In our study, there were no cases of small bowel obstruction, but 1 vesiciovaginal fistula was identified following cycle 6 . Other adverse events reported in the present study are infrequent and do not suggest exacerbation of toxicities by combining IP chemotherapy with IV bevacizumab.

Since 2006, there has been a great interest in improving IP based regimens to increase completion rates and reduce toxicity. There was also limited data as to whether IV bevacizumab could safely be combined with IP chemotherapy. The results of this study adds to the literature demonstrating the feasibility of this approach. Downstream effects on efficacy following modifications of the GOG 172 regimen need to be assessed further. While the PFS and OS in our small study are promising, the study population included less common histologies and stages such as low grade serous (4), carcinosarcoma, mucinous and clear cell carcinomas (1 each) as well as stage II disease (3). Given the primary objective was to assess the ability to administer the combined IP regimen, study eligibility was set sufficiently broad to permit a variety of patients who may benefit from a platinum/taxane based therapy.

Efficacy of modified regimens with IV bevacizumab is being evaluated in the GOG 252 trial (NCT00951496) which compares dose dense chemotherapy to two IP chemotherapy regimens (substitution of carboplatin for cisplatin, and reduced dose cisplatin $\left.\left(75 \mathrm{mg} / \mathrm{m}^{2}\right)\right)$. The contribution of IV bevacizumab to chemotherapy in ovarian cancer has been supported in two intravenous based phase III trials. Based on small studies, the addition of IV bevacizumab consolidation to IP therapy appears tolerable with no enhancement of acute or chronic toxicities. Validation of this concept in terms of efficacy and safety will be assessed with the forthcoming results of GOG 252(NCT00951496).

\section{References}

1. Jemal A, Siegel R, Xu J (2005) Cancer Statistics. Cancer J Clin 60: 277-300.

2. Cannistra SA (2004) Cancer of the ovary. N Engl J Med 351: 2519-2529. [Crossref]
3. Markman M, Bundy BN, Alberts DS, Fowler JM, Clark-Pearson DL, et al. (2001) Phase III trial of standard-dose intravenous cisplatin plus paclitaxel versus moderately high-dose carboplatin followed by intravenous paclitaxel and intraperitoneal cisplatin in small-volume stage III ovarian carcinoma: an intergroup study of the Gynecologic Oncology Group, Southwestern Oncology Group, and Eastern Cooperative Oncology Group. J Clin Oncol 19: 1001-1007. [Crossref]

4. Alberts DS, Liu PY, Hannigan EV, O’Toole R, Williams SD, et al. (1996) Intraperitoneal cisplatin plus intravenous cyclophosphamide versus intravenous cisplatin plus intravenous cyclophosphamide for stage III ovarian cancer. N Engl J Med 335: 19501955. [Crossref]

5. Armstrong DK, Bundy B, Wenzel L, Huang HQ, Baergen R, et al. (2006) Intraperitoneal cisplatin and paclitaxel in ovarian cancer. $N$ Engl J Med 354: 34-43. [Crossref]

6. Wenzel L, Huang H, Armstrong D (2007) Heath related quality of life during and after peritoneal versus intravenous chemotherapy for optimally debulked ovarian cancer: A Gynecologic Oncology Group Study. J Clin Oncol 25: 437-443. [Crossref]

7. Burger RA, Sill MW, Monk BJ, Greer BE, Sorosky JI (2007) Phase II trial of bevacizumab in persistent or recurrent epithelial ovarian cancer or primary peritoneal cancer: A Gynecologic Oncology Group Study. J Clin Oncol 25: 5165-5171. [Crossref]

8. Cannistra SA, Matulonis UA, Penson RT, Hambleton J, Dupont J, et al. (2007) Phase Il study of bevacizumab in patients with platinum-resistant ovarian cancer or peritoneal serous cancer. J Clin Oncol 25: 5180-5186. [Crossref]

9. Garcia AA, Hirte H, Fleming G, Yang D, Tsao-Wei DD, et al. (2008) Phase II clinical trial of bevacizumab and low-dose metronomic oral cyclophosphamide in recurrent ovarian cancer: a trial of the California, Chicago, and Princess Margaret Hospital phase II consortia. J Clin Oncol 26: 76-82. [Crossref]

10. Burger R, Brady M, Bookman M, Fleming G, Monk B, et al. (2011) Incorporation of bevacizumab in the primary treatment of ovarian cancer. N Engl J Med 365: 2473-2483. [Crossref]

11. Perren TJ, Swart AM, Pfisterer J, Ledermann JA, Pujade-Lauraine E, et al. (2011) A phase 3 trial of bevacizumab in ovarian cancer. $N$ Engl $J$ Med 365: 2484-2496. [Crossref]

12. Randall LM, Burger RA, Nguyen H, Kong G, Bookman MA, et al. (2013) Outcome differences in patients with advanced epithelial ovarian, primary peritoneal and fallopian tube cancers treated with and without bevacizumab. Gynecol Oncol.

13. Oza TJP AM, Swart AM, Schroder W, Pujade-Lauraine E, Havsteen H, et al. (2013) ICON7: final overall survival results in the GCIG phase III randomized trial of bevacizumab in women with newly diagnosed ovarian cancer. Eur J Cancer 49: LBA 6.

14. Almadrones L, McGuire DB, Walczak JR, Florio CM, Tian C (2004) Psychometric evaluation of two scales assessing functional status and peripheral neuropathy associated with chemotherapy for ovarian cancer: A Gynecologic Oncology Group Study. Oncol Nurs Forum 31: 615-623. [Crossref]

15. Trimble EL (2006) NCI Clinical Announcement on Intraperitoneal Chemotherapy in Ovarian Cancer.

16. Gould N, Sill MW, Mannel RS, Thaker PH, DiSilvestro PA, et al. (2012) A phase I study with an expanded cohort to assess feasibility of intravenous docetaxel, intraperitoneal carboplatin and intraperitoneal paclitaxel in patients with previously untreated ovarian, fallopian tube or primary peritoneal carcinoma: A Gynecologic Oncology Group study. Gynecol Oncol 127: 506-510. [Crossref]

17. Don S. Dizon, Michael W. Sill, Natalie Gould, Stephen C. Rubin, S. Diane Yamada, et al. (2011) Phase I feasibility study of intraperitoneal cisplatin and intravenous paclitaxel followed by intraperitoneal paclitaxel in untreated ovarian, fallopian tube, and primary peritoneal carcinoma: A Gynecologic Oncology Group Study. Gynecol Oncol 123: 182-186. [Crossref]

18. Morgan MA, Sill MW, Fujiwara K, Greer B, Rubin SC, Degeest K, et al. (2011) A phase I study with an expanded cohort to assess the feasibility of intraperitoneal carboplatin and intravenous paclitaxel in untreated ovarian, fallopian tube, and primary peritoneal carcinoma: A Gynecologic Oncology Group study. Gynecol Oncol 121: 264268. [Crossref]

19. McGuire WP, Hoskins WJ, Brady MF, Homesley HD, Creasman WT, et al. (1995) Assessment of dose-intensive therapy in suboptimally debulked ovarian cancer: A Gynecologic Oncology Group study. J Clin Oncol 13: 1589-1599. [Crossref]

20. Casper ES, Kelsen DP, Alcock NW, Lewis JL Jr. (1983) Ipcisplatin in patients with malignant ascites: pharmacokinetic evaluation and comparison with the iv route. Cancer Treat Rep 67: 235-238. [Crossref]

21. Konner JA, Grabon DM, Gerst SR, Iasonos A, Thaler H, et al. (2011) Phase II study of intraperitoneal paclitaxel plus cisplatin and intravenous paclitaxel plus bevacizumab 
Lanneau GL (2015) A Phase II trial of intravenous bevacizumab, paclitaxel and intraperitoneal cisplatin followed by intravenous bevacizumab maintenance for treatment of stage II-III ovarian cancer

as adjuvant treatment of optimal stage II/III epithelial ovarian cancer. J Clin Oncol 29: 4662-4668. [Crossref]

22. Barlin JN, Dao F, Bou Zgheib N, Ferguson SE, Sabbatini PJ, et al. (2012) Progressionfree and overall survival of a modified outpatient regimen of primary intravenous/ intraperitoneal paclitaxel and intraperitoneal cisplatin in ovarian, fallopian tube, and primary peritoneal cancer. Gynecol Oncol 125: 621-624. [Crossref]

23. Tewari D, Java JJ, Salani R, Armstrong DK (2015) Long term survival advantage and prognostic factors associated with intraperitoneal chemotherapy treatment in advanced ovarian cancer: A Gynecologic Oncology Group Study. J Clin Oncol 33: 1460-1466.

24. Walker JL, Armstrong DK, Huang HQ, Fowler J, Webster K, et al. (2006) Intraperitoneal catheter outcomes in a phase III trial of intravenous versus intraperitoneal chemotherapy in optimal stage III ovarian and primary peritoneal cancer: A Gynecologic Oncology Group Study. Gynecol Oncol 100: 27-32. [Crossref]
25. Wenzel LB, Huang HQ, Armstrong DK, Walker JL, Cella D (2007) Health-related quality of life during and after intraperitoneal versus intravenous chemotherapy for optimally debulked ovarian cancer: A Gynecologic Oncology Group Study. J Clin Oncol 25: 437-443. [Crossref]

26. Monk BJ, Huang HQ, Burger RA, Mannel RS, Homesley HD, et al. (2013) Patient reported outcomes of a randomized, placebo-controlled trial of bevacizumab in the front-line treatment of ovarian cancer: A Gynecologic Oncology Group Study. Gynecol Oncol 128: 573-578. [Crossref]

27. Penson RT, Huang HQ, Wenzel LB, Monk BJ, Stockman S, et al. (2015) Bevacizumab for advanced cervical cancer: patient-reported outcomes of a randomised, phase 3 trial (NRG Oncology-Gynecologic Oncology Group protocol 240). Lancet Oncol 16: 301311. [Crossref]

Copyright: (C2015 Lanneau GL. This is an open-access article distributed under the terms of the Creative Commons Attribution License, which permits unrestricted use, distribution, and reproduction in any medium, provided the original author and source are credited. 